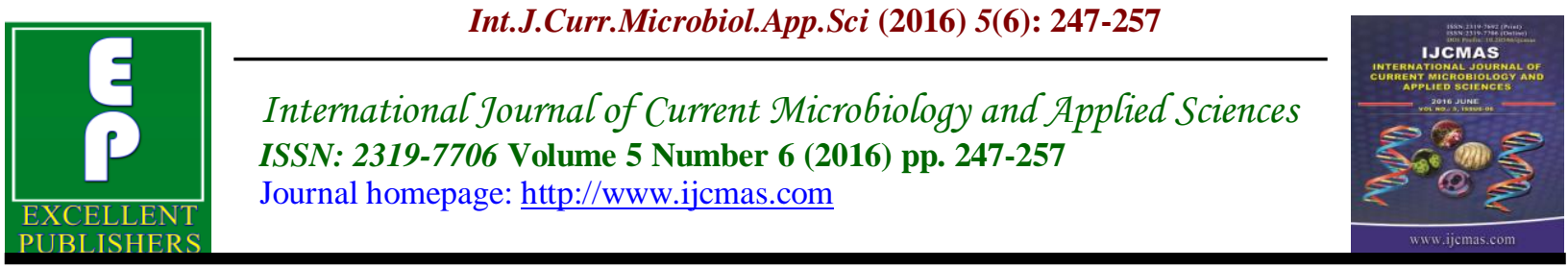

Review Article

http://dx.doi.org/10.20546/ijcmas.2016.506.028

\title{
Plant and Pathogens: Pathogen Recognision, Invasion and Plant Defense Mechanism
}

\author{
Sauban Musa Jibril ${ }^{1}$, Bello Hassan Jakada ${ }^{1 *}$, Ahmad Shehu Kutama ${ }^{2}$ \\ and Harisu Yunusa Umar ${ }^{1}$ \\ ${ }^{1}$ Faculty of Applied Sciences, Jodhpur National University, India \\ ${ }^{2}$ Federal University, Dutse, Nigeria \\ *Corresponding author
}

\author{
A B S T R A C T
}

\section{Keywords}

Plant Pathogens,

Fungi,

Bacteria,

Virus,

Nematodes,

Pathogen

Recognition,

Plant Defense

Mechanism and

Host Defenses.

Article Info

Accepted:

12 May 2016

Available Online:

10 June 2016
A plant pathogen is an organism or a virus that can inhabit and survive on plants and can compromise the health of the plant causing disease symptoms. Plant pathogens may be fungi, bacteria, viruses or nematodes, covering different levels of host specificity, some with a broad host range, others host species specific. Fungi belong to eukaryote group of organisms which also includes moulds, yeast and mushrooms. Most of the over 100,000 species of fungi are saprophytes. However, over 20,000 species of fungi are parasites and cause disease in crops and plants, Fungi can cause general or localized signs and/or symptoms. In the majority of cases, fungal infections cause general necrosis of host tissue and often cause stunting, distortions and abnormal changes in plant tissue and organs. Bacteria are single-celled microorganisms, generally ranging from 1-2 $\mu \mathrm{m}$ in size that cannot be seen with the unaided eye. Plant associated bacteria may be beneficial or detrimental. There are around 200 species of phytopathogenic bacteria and almost all of them are parasites within the plant, on its surface, in plant debris or in the soil as saprophytes. They include leaf spots, blights, wilts, scabs, cankers and soft rots of roots, storage organs and fruit, and overgrowth. Viruses are infectious pathogens that are too small to be seen with a light microscope, but despite their small size they can cause chaos. The simplest viruses are composed of a small piece of nucleic acid surrounded by a protein coat. All viruses are obligate parasites that depend on the cellular machinery of their hosts to reproduce. Viruses are not active outside of their hosts, and this has led some people to suggest that they are not alive and most viruses infect only one type of host. Most plant viruses are actively transmitted from infected to healthy plants by a living organism called a vector. Plant-feeding arthropods, nematodes and plant-parasitic fungi are the major types of vector organisms for plant viruses. Nematodes are roundworms, similar to the animal parasites encountered in livestock and pets. Soil- dwelling nematodes are both good guys and bad guys in crop production. Plant-pathogenic nematodes feed only on plants; in fact, they cannot sustain themselves on anything else. When their numbers increase to high levels, they can severely injure or kill plants, especially seedlings. In lower, more typical numbers, they can cause yield losses without causing obvious symptoms, and they can be involved in disease interactions with other pathogens, including viruses, fungi, and bacteria. Plant-parasitic nematodes range from $250 \mathrm{um}$ to $12 \mathrm{~mm}$ in length, averaging $1 \mathrm{~mm}$, to about $15-35$ um in width. The ability of plants to respond to challenge by potential pathogens implies that plants recognise these potential pathogens as 'non-self. Plants defend themselves against pathogens by a combination of weapons termed as host resistsnce from two arsenals: (1) structural characteristics that act as physical barriers and inhibit the pathogen from gaining entrance and spreading through the plant and (2) biochemical reactions that take place in the cells and tissues of the plant and produce substances that are either toxic to the pathogen or create conditions that inhibit growth of the pathogen in the plant. 


\section{Introduction}

Plant disease is an impairment of the normal state of the plant that interrupts or modifies its vital functions. Disease is a response to specific causal agents (biotic or abiotic), inherent defects of the plant or combinations of these factors. Disease comprises of two terms, "dis" and "ease" which means uneasiness (Ravichandra, 2013). Plant pathogens pose an enormous problem for global food security populations of plant pathogens are variable in time and space. Plants exist in a world filled with microorganism. They continue to grow in the same location throughout the growing season or for many years, as in the case of perennial plants. Their surfaces are constantly exposed to bacteria, fungi, nematodes, and possibly parasitic plants.

They may be inoculated with viruses during feeding by insects or by other vectors. Plant pathogens have made many adaptations to enable them to invade plants, overcome plant defense mechanisms, and colonize plant tissues for growth, survival, and reproduction. Once established inside the plant, they have at least temporarily escaped the intense competition from saprophytic organisms on plant surfaces and in the soil. Therefore, for a pathogen to infect a plant, it must be able to make its way in to and through the plant, obtain nutrients from the plant, and neutralize the defense reactions of the plant. (Bollen, et al., 1989).

Pathogen is an organism or virus capable of causing disease in a particular host or range of host (Anonymous, 1973). Most but not all pathogen are also parasites in that they derive the materials they need for existence from a living plant as distinct from saprophytes which derive the material from dead organic material (Mehrotra, 1980).

\section{Plants and Pathogens}

A plant pathogen is an organism or a virus that can inhabit and survive on plants and can compromise the health of the plant causing disease symptoms. Plant pathogens may be fungi, bacteria, viruses or nematodes, covering different levels of host specificity, some with a broad host range, others host species specific (Lisbeth Mikkelsen et al., 2006). A pathogen that causes diseases is termed virulent, pathogen that does not cause diseases is termed avirulent. For a pathogen to causes a disease in plant three parameters must be available without which disease would not occur, this is known as disease triangle (figure 1). The existence of disease caused by a biotic agent absolutely requires the interaction of a susceptible host, a virulent pathogen and an environment favorable for disease development conversely plant disease is prevented upon elimination of any one of these causal components (Ravichandra, 2013).

Many plant pathogens act like "silent thieves" who want to steal money locked inside of a bank vault. These thieves use specialized tools designed to disable the bank's security system and unlock the vault without being detected. In a similar way, many pathogens establish intimate connections with their hosts in order to suppress plant defenses and promote the release of nutrients. Pathogens that keep their host alive and feed on living plant tissue are called biotrophs. Examples of biotrophic pathogens include the powdery mildew fungus Blumeria graminis and the bacterial rice pathogen Xanthomonas oryzae. Other pathogens resort to brute force like thieves who blast open a bank vault with explosives. These pathogens often produce toxins or tissue-degrading enzymes that overwhelm plant defenses and promote 
the quick release of nutrients. These pathogens are called necrotrophs, and examples include the gray mold fungus Botrytis cinerea and the bacterial soft-rot pathogen Erwinia carotovora. Some pathogens are biotrophic during the early stages of infection but become necrotrophic during the latter stages of disease. These pathogens are called hemibiotrophs and include the fungus Magnaporthe grisea, the causative agent of rice blast disease (Brian and Gwyn, 2008).

\section{Fungi}

Fungi belong to eukaryote group of organisms which also includes moulds, yeast and mushrooms. The English word fungus is directly adopted from the latin fungus (Ravichandra, 2013). Fungi are spore forming, non-chlorophytic, Eukaryotic (cells having true nuclei) organisms and most of the true fungi are filamentous and branched. Most of the over 100,000 species of fungi are saprophytes. However over 20,000 species of fungi are parasites and cause disease in crops and plants (USEPA2005). Fungal parasites are by far the most prevalent plant pathogenic organism. All plants are attack by one species or another of phytopathogenic fungi. Individual species of fungi can parasitize one or many different kinds of plants (Tom Schultz, 2007).

Fungi can cause general or localized signs and/or symptoms. In the majority of cases, fungal infections cause general necrosis of host tissue and often cause stunting, distortions and abnormal changes in plant tissue and organs. The most distinctive and easily identifiable characteristics of fungal infections are the physical presence of signs of the pathogen. Signs include hyphae, mycelia, fruiting bodies and spores of the fungal pathogen are significant clues to proper identification and diagnosis of a disease. The fruiting bodies of fungi range from microscopic to macroscopic. They come in many shapes and configurations and have their individual characteristics. The fruiting bodies, along with spores, and mycelium, in most cases can lead to an accurate identification of the disease. The following symptoms are common in fungal infections whether alone or in combination with other fungal pathogen (Moore, Randy 1998,). The body, or thallus, of most of the higher fungi is called a mycelium (pl. mycelia). The mycelium is made up of thread-like structures called hyphae (sing. hypha). Hyphae grow only from their tips, and under favorable conditions can grow indefinitely. Hyphae, most often, are partitioned by cross walls called septa (sing. septum). Septate hyphae are divided into individual cells by these internal walls. Hyphae produce specialized simple or branched projections called haustoria (sing. Haustorium). Haustoria penetrate the host tissue and act as nutrient absorbing organs. Haustoria contain nuclei and a concentrated number of mitochondria. The haustoria do not rupture the host cell protoplasmic membrane but invaginates itself into the cell thus greatly increasing the absorptive surface of the fungus (Tom Schultz, 2007).

\section{Bacteria}

Bacteria are single-celled microorganisms, generally ranging from $1-2 \mu \mathrm{m}$ in size that cannot be seen with the unaided eye. Plant associated bacteria may be beneficial or detrimental. All plant surfaces have microbes on them (termed epiphytes), and some microbes live inside plants (termed endophytes). Some are residents and some are transient. Bacteria are among the microbes that successively colonize plants as they mature. Individual bacterial cells cannot be seen without the use of a microscope, however, large populations of 
bacteria become visible as aggregates in liquid, as biofilms on plants, as viscous suspensions plugging plant vessels, or colonies on petri dishes in the laboratory. For beneficial purposes or as pathogens, populations of $106 \mathrm{CFU}$ (colony-forming units/milliliter) or higher are normally required for bacteria to function as biological control agents or cause infectious disease. Plant pathogenic bacteria cause many serious diseases of plants throughout the world (Vidhyasekaran, 2002); but fewer than fungi or viruses, and they cause relatively less damage and economic cost (Kennedy and Alcorn, 1980). Most plants, both economic and wild, have innate immunity or resistance to many pathogens. However, many plants can harbor plant pathogens without symptom development most phytopathogenic bacteria are aerobic (live in the presence of oxygen) and some are facultative anaerobes which can grow with or without oxygen (Vidaver and Lambrecht, 2004).

The primary way nitrogen is supplied to plants is through the mineralization of organic material in the soil, however nitrogen fixation by bacteria such as Rhizobium spp. and Cyanobacteria spp. There are around 200 species of phytopathogenic bacteria and almost all of them are parasites within the plant, on its surface, in plant debris or in the soil as saprophytes.

Dissemination of bacteria can be accomplished by several means. Some bacteria can survive on inanimate objects, in water or inside insects. Symptoms of bacterial infection in plants are much like the symptoms in fungal plant disease. They include leaf spots, blights, wilts, scabs, cankers and soft rots of roots, storage organs and fruit, and overgrowth (Tom Schultz, 2006).

\section{Virus}

Viruses are infectious pathogens that are too small to be seen with a light microscope, but despite their small size they can cause chaos. The simplest viruses are composed of a small piece of nucleic acid surrounded by a protein coat. As is the case with other organisms, viruses carry genetic information in their nucleic acid which typically specifies three or more proteins. All viruses are obligate parasites that depend on the cellular machinery of their hosts to reproduce. Viruses are not active outside of their hosts, and this has led some people to suggest that they are not alive. All types of living organisms including animals, plants, fungi, and bacteria are hosts for viruses, but most viruses infect only one type of host. Viruses cause many important plant diseases and are responsible for losses in crop yield and quality in all parts of the world (Rose and Valerian, 2006). Only relatively few viruses, such as TMV, rely on long-term (up to decades) survival in the environment and on passive mechanical transmission from plant to plant (Ford and Evans 2003). Most plant viruses are actively transmitted from infected to healthy plants by a living organism called a vector. Plant-feeding arthropods, nematodes and plant-parasitic fungi are the major types of vector organisms for plant viruses (Walkey, 1991). Among these, aphids and whiteflies are capable of transmitting the largest number of virus species. Most viruses are actively transmitted to healthy plants in a matter of seconds, hours, or days by vectors. In addition, some viruses are transmitted from infected plants when these plants are vegetatively propagated, for example, through tubers or grafting, or 'vertically' through seeds or pollen from infected plants. This type of transmission is particularly important for virus survival during the winter. 


\section{Nematodes}

Nematodes are roundworms, similar to the animal parasites encountered in livestock and pets. Soil- dwelling nematodes are both good guys and bad guys in crop production. Plant-pathogenic nematodes feed only on plants; in fact, they cannot sustain themselves on anything else. When their numbers increase to high levels, they can severely injure or kill plants, especially seedlings. In lower, more typical numbers, they can cause yield losses without causing obvious symptoms, and they can be involved in disease interactions with other pathogens, including viruses, fungi, and bacteria. Virtually every field has one or more potentially damaging nematode species (Terry Niblack, 2006).

Plant-parasitic nematodes occur in all sizes and shapes. The typical nematode shape is a long and slender worm-like animal, but often the adult animals are swollen and no longer even resemble worms. Plant-parasitic nematodes range from $250 \mathrm{um}$ to $12 \mathrm{~mm}$ in length, averaging $1 \mathrm{~mm}$, to about $15-35 \mathrm{um}$ in width. While nematodes may look dramatically different, they all share some common features. Nematodes feed on all parts of the plant, including roots, stems, leaves, flowers and seeds. Nematodes feed from plants in a variety of ways, but all use a specialized spear called a stylet (Chen, $e t$ al., 2004). Many plant-parasitic nematodes feed on the roots of plants. The feeding process damages the plant's root system and reduces the plant's ability to absorb water and nutrients. Typical nematode damage symptoms are a reduction of root mass, a distortion of root structure and/or enlargement of the roots. Nematode damage of the plant's root system also provides an opportunity for other plant pathogens to invade the root and thus further weakens the plant. Direct damage to plant tissues by shoot-feeding nematodes includes reduced vigor, distortion of plant parts, and death of infected tissues depending upon the nematode species (Lambert and Bekal, 2002).

\section{Pathogen Recognition}

The ability of plants to respond to challenge by potential pathogens implies that plants recognise these potential pathogens as 'nonself. While mammals use antigen-antibody interactions to recognise non-self, plants recognise a vast array of signals originating from micro-organisms and the environment to elicit defense responses (David and John, 1997).

\section{Plant Defense Mechanism}

Plants defend themselves against pathogens by a combination of weapons termed as host resistsnce from two arsenals: (1) structural characteristics that act as physical barriers and inhibit the pathogen from gaining entrance and spreading through the plant and (2) biochemical reactions that take place in the cells and tissues of the plant and produce substances that are either toxic to the pathogen or create conditions that inhibit growth of the pathogen in the plant. The combination of structural characteristics and biochemical reactions employed in the defense of plants are different host-pathogen systems. However, whatever the kind of defense or resistance a host plant employs against a pathogen or against an abiotic agent, it is ultimately controlled, directly or indirectly by the genetic material (genes) of the host plant and of the pathogen (Tom Schultz, 2007).

\section{Non Host Resistance}

When a plant resist the attack of pathogenic organism which is otherwise not the host of that pathogen is termed as non-host 
resistance-e.g. potato late blight pathogen do not infect apple or wheat plant and similarly apple pathogen like V. inaequalis do not attack potato. Similarly, the fungus that causes powdery mildew on wheat (Blumeria (Erysiphe) graminis $f$.sp .tritici) does not infect barley and vice versa, the fungus that causes powdery mildew on barley (B. graminis $f$. sp. hordei) does not infect wheat, and so on (Sharma, 2011).

\section{Host Defenses}

Plants defend themselves against pathogens by a combination of weapons termed as host resistsnce from two arsenals: constitutive and induced. Constitutive includes physical barriers (Structural) and phytoanticipins (Biochemical). Inducible involve structural comprises of corky, absiccion layers, tylose etc. and Biochemical which include phytoalexins, hypersensitive Response and systemic acquired response (SAR) (Sharma, 2011).

\section{Structural Defenses}

The importance of the cuticle as a barrier to penetration has been demonstrated by the dependence of many pathogens on adhesion and the subsequent release of cutindegrading enzymes at the time of penetration.

Although cutin-degrading enzymes are also secreted by many saprophytic fungi and bacteria, their primary activity is to allow access to cellulose in plant cell walls as a nutritional substrate. Different forms of cutin-degrading enzymes are used by pathogens to puncture the cell wall. The activity of this type of cutinolytic enzyme in isolates of Fusarrum solani, F. sp. pisi is directly related to their aggressiveness on pea stems, indicating that pathogens unable to dissolve the cuticle at the point of penetration are excluded (David and John
1997). Waxes on leaf and fruit surfaces forms a water-repellant surface, thereby preventing the formation of a film of water on which pathogens might be deposited and germinate (fungi) or multiply (bacteria). also plant structures like tough and thick epidermal cells play a role in defense against pathogens, These are important factors in the resistance of some plants to certain pathogens by making direct penetration fungal pathogens difficult or impossible. Many pathogenic fungi and bacteria enter plants only through stomata. The structure of stomata e.g. a very narrow entrance and broad, elevated guard cells, may confer resistance to some varieties against certain bacterial pathogens (Tom Schultz, 2006). Cell walls contain proteins and enzymes that actively work to reshape the wall during cell growth yet thicken and strengthen the wall during induced defense.

When a plant cell detects the presence of a potential pathogen, enzymes catalyze an oxidative burst that produces highly reactive oxygen molecules capable of damaging the cells of invading organisms. Reactive oxygen molecules also help strengthen the cell wall by catalyzing cross-linkages between cell wall polymers, and they serve as a signal to neighboring cells that an attack is underway. Plant cells also respond to microbial attack by rapidly synthesizing and depositing callose between the cell wall and cell membrane adjacent to the invading pathogen. Callose deposits, called papillae, are polysaccharide polymers that impede cellular penetration at the site of infection, and these are often produced as part of the induced basal defense response (Brian C.F and Gwyn A.B, 2008).

\section{Induced Structural Defenses}

These are usually not present in the plants but are produce in response to invading pathogens. 
Fig.1 Disease triangle

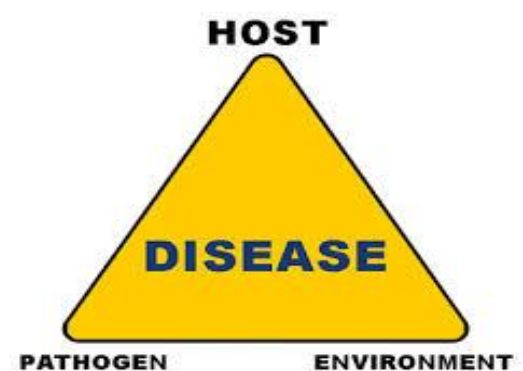

Fig.2 Bacterial cell

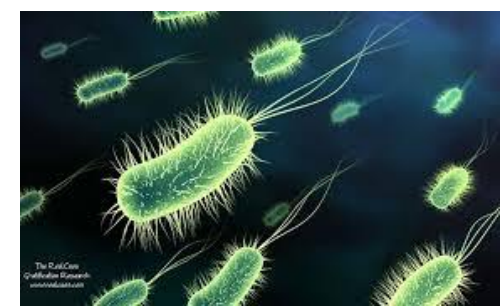

Source: Hopeful-link.biologist.com

Fig.3 Bacterial wilt

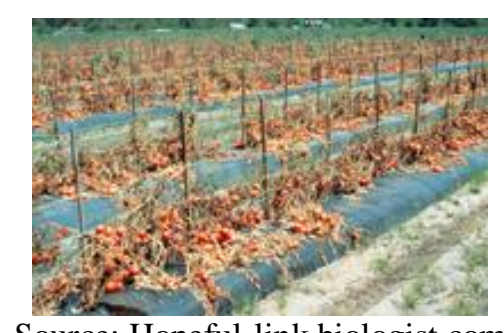

Source: Hopeful-link.biologist.com

Fig.4 Body structure of nematode. Source: Lambert, K. and S. Bekal. 2002

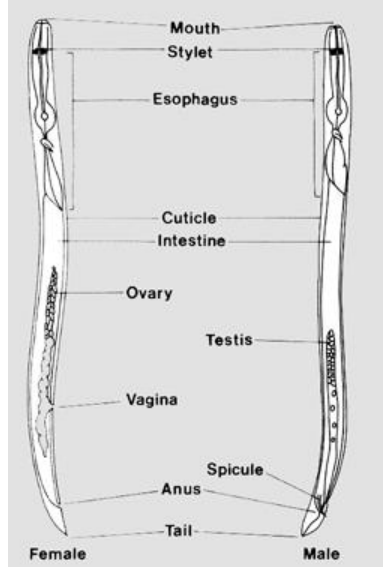


Fig.5 Some plant nematodes Source: Lambert, K. and S. Bekal. 2002

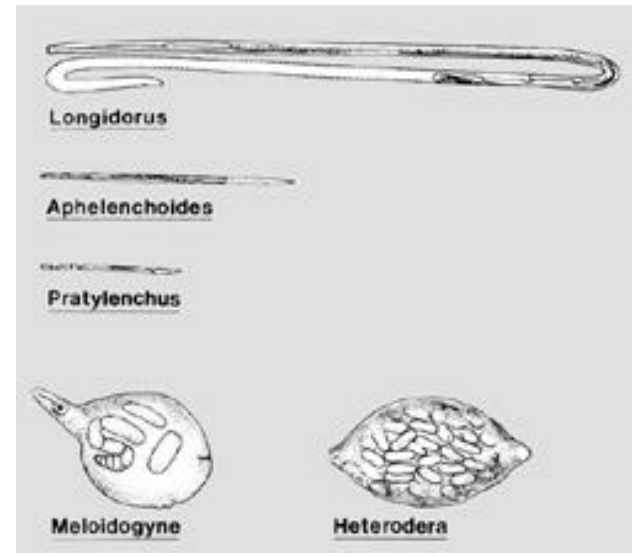

Fig.6 Plant defense response

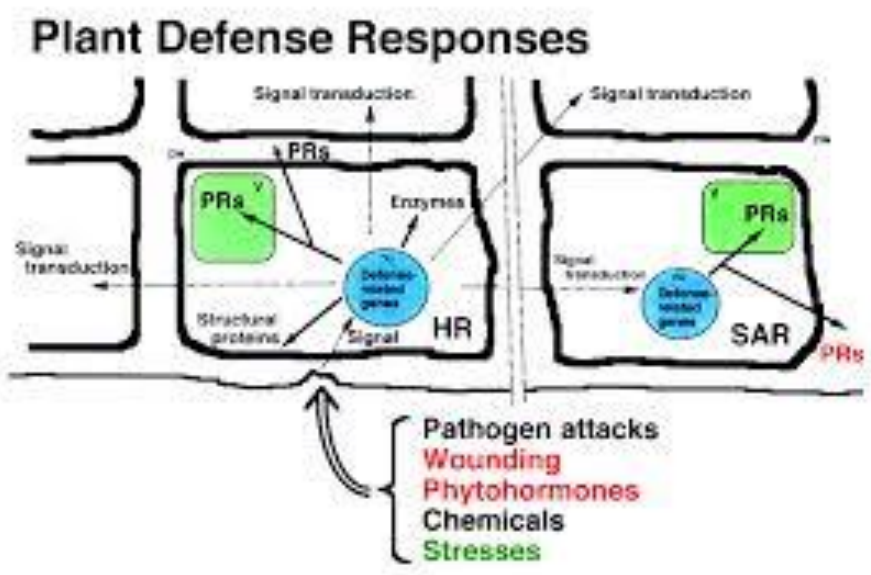

Fig.7 Defense response by cell wall

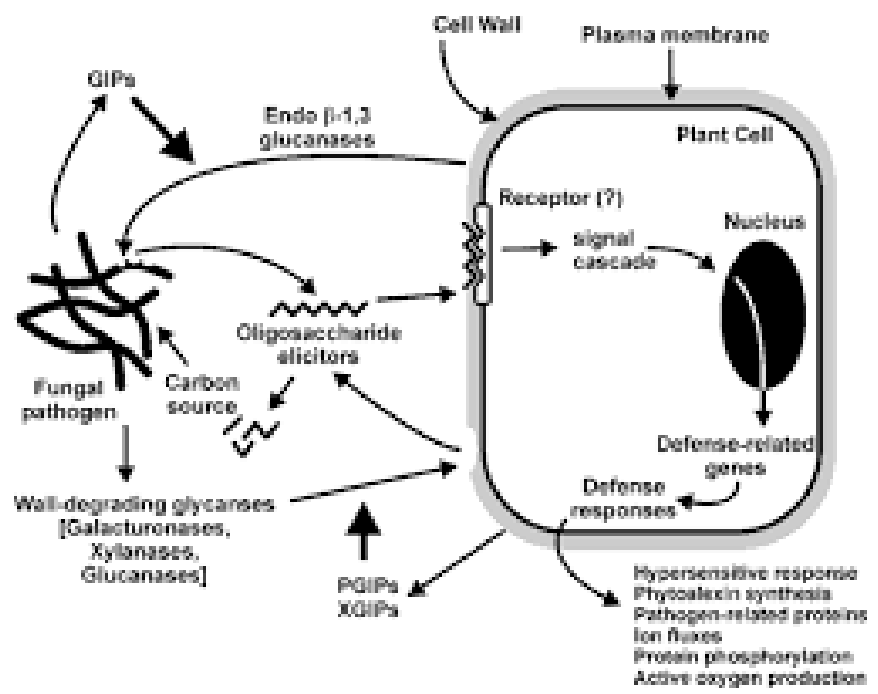


Fig.8 HR lesion on an Arabidopsis leaf

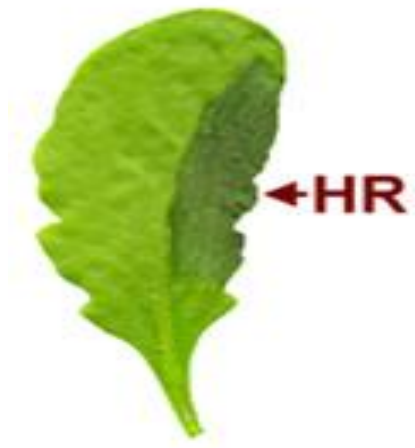

Source: Brian C.F and Gwyn A.B 2008

\section{Cork layers Formation}

Infection by fungi or bacteria and even by some viruses and nematodes frequently induces plants to form several layers of cork cells beyond the point of infection, apparently as a result of stimulation of the host cells by substances secreted by the pathogen.

\section{Formation of Abscission Layers}

An abscission layer consists of gap formed between two circular layesrs of leaf cells surroding the locus of infection. Upon infection, the middle lamella between these two layers of cells is dissolved throughout the thickness of the leaf, completely cutting off the central area of infection from the rest of the leaf.

\section{Formation of Tyloses}

Tyloses are overgrowths of the protoplast of adjacent living parenchymatous cells which protrude into xylem vessels through pits. Tyloses form an impenetrable barrier to the movement of water and nutrients.

\section{Deposition of Gums}

The defensive role of gums stems from the fact that they are deposited quickly in the intercellular spaces and within the cells surrounding the locus of infection, thus forming an impenetrable barrier that completely encloses the pathogen (Tom Schultz, 2006).

\section{Biochemical Defenses}

Exudates on the surfaces of plants or compounds in plant cells may stimulate or inhibit the development of pathogens. Sometimes, plants resist infection because they do not provide the pathogen with its required nutrients. Resting spores of pathogens such as Spongospora subterranea (powdery scab of potato), Urocgstls agropgri (flag or leaf smut of wheat) and Plasmodtophora brassicae (club root of crucifers) and eggs of the potato cyst nematode, Globodera rostochiensis, require specific substances to stimulate germination or hatching. These are provided in secretions from certain plants, including potential hosts. Plants that fail to secrete these stimulators are resistant by default (David G. and John 1997). Plant chemicals can be divided into two major categories: primary metabolites and secondary metabolites. Primary metabolites are substances produced by all plant cells that are directly involved in growth, development, or reproduction. Examples include sugars, proteins, amino acids, and nucleic acids. Secondary metabolites are not directly 
involved in growth or reproduction but they are often involved with plant defense. These compounds usually belong to one of three large chemical classes: terpenoids, phenolics, and alkaloids (Brian C.F. and Gwyn A.B, 2008).

\section{The Hypersensitive response}

The most common expression of host resistance, and a frequent expression of nonhost resistance, is the hypersensitive response (HR), a rapid death of cells at the infection site that is associated with pathogen limitation as well as with defense gene activation. Some of the avr genes that control the HR response to bacterial pathogens in resistant hosts also seem to act as pathogenicity (pth) genes in susceptible plants. Gabriel, (1999) has recently argued that, because of horizontal gene transfer between bacteria, some avr-genes may be maladapted pth- genes that 'inad- vertently' elicit an HR in host and non-host plants. Such a situation seems particularly likely if the non-hosts have R-gene products with which avr-gene products can inter- act. Whether all examples of the HR in non-host interactions with bacteria are caused by avrgene action is uncertain, and the roles of harpins and bacterial flagellin as nonspecific elicitors of the HR remain to be determined (Michèle Heath, 2000). Once the hypersensitive response has been triggered, plant tissues may become highly resistant to a broad range of pathogens for an extended period of time. This phenomenon is called systemic acquired resistance (SAR) and represents a heightened state of readiness in which plant resources are mobilized in case of further attack. Researchers have learned to artificially trigger SAR by spraying plants with chemicals called plant activators. These substances are gaining favor in the agricultural community because they are much less toxic to humans and wildlife than fungicides or antibiotics, and their protective effects can last much longer (Brian C.F. and Gwyn A.B, 2008).

\section{Prospect}

The interaction between plant and pathogen plays a critical role in understanding disease, disease cycle and to know where, when is the best time and at what state of condition to tackle the disease. Fungi that require an intermediate host are starved by removing the intermediate in the life cycle of the pathogen, while those that do not require intermediate host are tackled with bio or chemical pesticide along with cultural practices. Bacterial and Viral diseases require integrated pest management practices i.e integration of cultural, biological and chemical control. More research is required to assess the viability of using induced resistance as it tends to be the new avenue in controlling plant diseases.

\section{Abbreviations}

AVR avirulence

HR hypersensitive response

PCD programmed cell death

PR1 pathogenesis-related 1

PTH pathogenicity

$\mathbf{R}$ resistance

ROS reactive oxygen species

TIR Toll/Interleukin-1 receptor

SAR systemic acquired resistance

\section{References}

Anne, K., Vidaver, Patricia, A., Lambrecht. 2004. Bacteria as plant pathogens. The Plant Health Instructor. DOI: 10.1094/PHI-I-2004-0809-01

Annonymous. 1973. Federation of British plant pathologist. A guide to the use of terms in plant pathology. Phytopat., page 17.

Bollen, G.J., Volker, D., Wijnen, A.P. 1989. Inactivation of soil-borne plant pathogens during small-scale composting of crop residues. Netherlands J. Plant Pathol., 
95: 19-30.

Brian, C.F., Gwyn, A.B. 2008. An Overview of Plant Defenses against Pathogens and Herbivores. The Plant Health Instructor, DOI: 10.1094/PHI-I-2008-0226-01

Chen, Z.X., D.W. Dickson. 2004. Nematology: Advances and Perspectives Vol. 1: Nematode Morphology, Physiology and Ecology, CABI:Walllingford.

David Guest, John Brown. 1997. Plant pathogens and plant diseases. Rockvale publications national library of Australia ISBN 1-86389-439. Page 263-260. Edited by J.F.Brown \& H.J, Ogle

Ford, R., T. Evans. 2003. Tobacco mosaic virus. The Plant Health Instructor. DOI: 10.1094/PHI-K-2003052801

Gabriel, D.W. 1999. Why do pathogens carry avirulence genes? Physiol. Mol. Plant Pathol., 55: 205-214.

Kennedy, B.W., Alcorn, S.M. 1980. Estimates of U.S. crop losses to prokaryote plant pathogens. Plant Dis., 64: 674-676.

Lambert, K., S. Bekal. 2002. Introduction to Plant-Parasitic Nematodes. The Plant Health Instructor. DOI:10.1094/PHI-I2002-1218-01 Revised 2009 by the Education Center Editorial Board

Lisbeth Mikkelsen, John Elphinstone, Dan Funck Jensen. 2006. Literature review on detection and eradication of plant pathogens in sludge, soils and treated biowaste

Mehrotra, R.S. 1980. plant pathology. Tata McGraw-Hill, New Delhi, page 771.

Michèle C. Heath. 2000. Nonhost resistance and nonspecific plant defenses. Botany
Department, University of Toronto, Curr. Opi. Plant Biol., 3: 315-319- see front matter (C) 2000 Elsevier Science Ltd. All rights reserved.

Moore, Randy. $1998 . \quad$ Botany http:/www.mycolog.com/fifthloc.html

Sharma, P.N. 2011. Department of Plant Pathology, CSK HPKV, Palampur (H.P)

Ravichandra, N.G. 2013. Fundamentals of plant pathol., PHI Learning, New Delhi. ISBN 978-81-203-4703-8 page 43.

Rose, C., Gergerich, Valerian, V., Dolja. 2006. Introduction to Plant Viruses, the Invisible Foe. The Plant Health Instructor, DOI: 10.1094/PHI-I-20060414-01

Terry Niblack Illinois. Agronomy Handbook Department of Crop Sciences tniblack@illinois.edu

Tom Schultz. 2007. Jim Cooper, Master Gardener WSU County Extension, SJC (C) June 5, 2007

U.S. Environmental Protection Agency, 1998. Interagency Workgroup on Air Quality Modeling. J. Air Poll. Control Assoc., 23: 598-600.

Vidaver, A.K., P.A. Lambrecht. 2004. Bacteria as plant pathogens. The Plant Health Instructor, DOI: 10.1094/PHI-I-20040809-01

Vidhyasekaran, P. 2002. Bacterial disease resistance in plants. Molecular biology and biotechnological applications. 452 pp. The Haworth Press, Binghamton, NY.

Walkey, D. 1991. Applied Plant Virology. 2nd edition. Chapman and Hall, London.

\section{How to cite this article:}

Sauban Musa Jibril, Bello Hassan Jakada, Ahmad Shehu Kutama and Harisu Yunusa Umar. 2016. Plant and Pathogens: Pathogen Recognision, Invasion and Plant Defense Mechanism. Int.J.Curr.Microbiol.App.Sci. 5(6): 247-257. doi: http://dx.doi.org/10.20546/ijcmas.2016.506.028 